\title{
Novel Conductive Nano-composite Ink Based on Poly Aniline, Silver Nanoparticles and Nitrocellulose
}

\author{
M. A. Abd El-Ghaffar ${ }^{1}$, K.A. Shaffei ${ }^{2}$, A.A. Fouad Zikry ${ }^{2}$, \\ Mona B. Mohamed ${ }^{3}$ and Khaled A.G. Marzouq ${ }^{2^{*}}$ \\ ${ }^{I}$ Polymers and Pigments Department, National Research \\ Centre, ${ }^{2}$ Chemistry Department, Faculty of Science, Helwan \\ University, Helwan and ${ }^{3}$ National Institute of Laser Enhanced \\ Science, Cairo University, Cairo, Egypt.
}

\begin{abstract}
CONDUCTING polymers have attracted much attention in view of scientific interest, simple preparation method and practical applications. This article demonstrates the preparation of an electrically conductive composite based on (poly aniline, silver nanoparticles, nitrocellulose resin) by mixing the three components with each other by sonication. Poly aniline (PANI) doped with $\mathrm{HCl}$ was prepared by chemical oxidation pathway using potassium peroxydisulphate while silver nanoparticles (Ag-NPs) was synthesized via chemical reduction process using oleic acid and oleyl amine. The prepared materials were characterized by spectroscopic measurements (FTIR, UV-vis, TEM), in addition to thermal analysis (TGA, DSC). The electrical conductivity was measured by four-point probe method. The achieved results indicated high performance properties for the nano-composite to be applied in conducting inks.
\end{abstract}

Keywords: Conductive ink, Poly aniline hydrochloride, Silver nano particles, Nitrocellulose and Polymer nano composite.

In the few recent years, electrically conductive nano-inks which contain nanosized conductive material have been attracting much attention ${ }^{(1)}$. The electrically conductive inks are composites of the polymers and electrically conductive materials where the polymeric materials provide the mechanical and processing properties while the electrically conductive materials provide the electrical properties ${ }^{(2)}$. Polyanilines have accepted a great importance with respect to the scientists due to its simple and easy synthetic methods, raw materials availability, lower cost, light weight, good environmental stability, and corrosion resistance; in addition to its various applications ${ }^{(3)}$. Because of the different properties of PANI so it has a wide applications such as, a conducting

*Corresponding Author: E-mail: khaled_science_he2007@yahoo.com. 
polymer, efficient corrosion inhibitors for steel protection ${ }^{(4)}$, lightweight rechargeable battery ${ }^{(5,6)}$. and electromagnetic shielding devices ${ }^{(7,8)}$. PANI is polymerized by both chemical and electrochemical polymerization ${ }^{(9)}$. The synthetic methods of conducting polymers, especially polyaniline include chemical and electrochemical pathways and it has a very simple acid/base doping/dedoping chemistry ${ }^{(10-13)}$. as shown in Scheme (1). One of the common synthesis methods of polyaniline is, the chemical oxidation of aniline using potassium peroxydisulphate or ammonium peroxydisulphate as initiators ${ }^{(14)}$ and hydrochloric acid as dopant ${ }^{(15)}$. PANI has its importance due to its good combination of low cost, stability and conductivity ${ }^{(16)}$. However, PANI is poor processing, rigid and non-film forming polymer ${ }^{(17)}$. Many articles were published to overcome with these problems and one of these ways is applied by dispersing PANI (or any other non film forming material having electrical conductivity) in a polymeric material having good mechanical and processing properties ${ }^{(2)}$. As reported by Veluru, J. B. et al. where PANI was dispersed in Poly Methyl Methacrylate (PMMA) ${ }^{(18)}$. Some of the most popular polymeric materials that used as binders are poly acrylates eg. PMMA, epoxy resin ${ }^{(19,20)}$, polyurethan $^{(21)}$. and polystyren ${ }^{(22)}$. where these materials have good mechanical properties and good processablity.

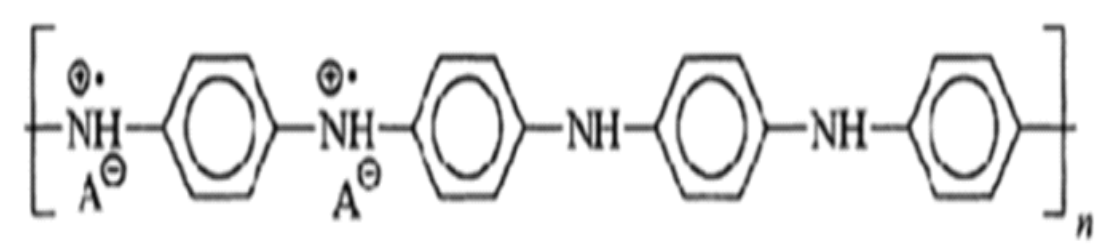

\section{Emeraldine Salt (Green)}
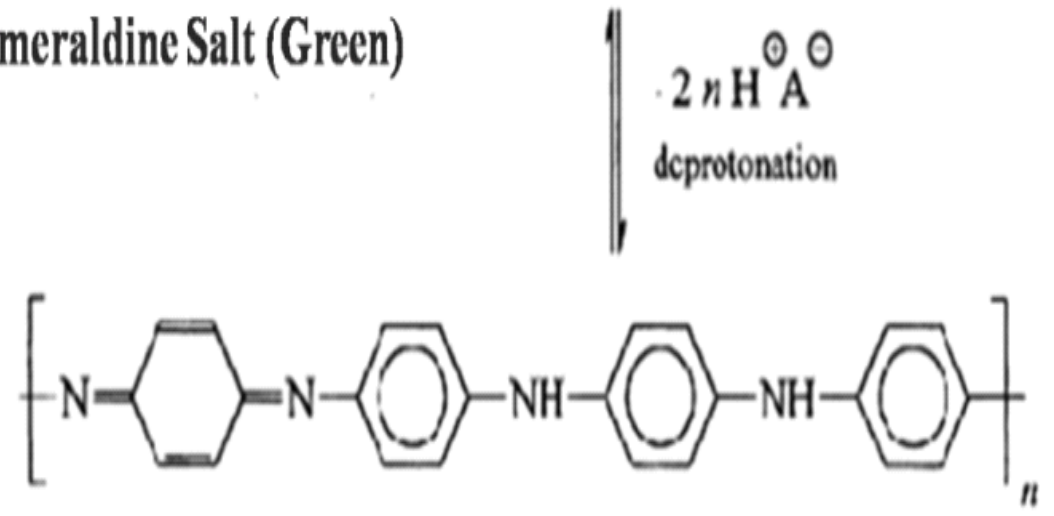

Emeraldime Base (Bliee)

Scheme 1. The conductive form (Emeraldine salt) and nonconductive form (Emiraldine base) of PANI ${ }^{(23)}$ 
Silver nanoparticles are one of the most popular nano-materials that used to disperse in organic polymers and considered the most attracted to researchers, but there are other different nano-materials such as: grapheme ${ }^{(24)}$, copper ${ }^{(25)}$, carbon nano-tubes ${ }^{(26)}$, oxides (e.g. $\mathrm{TiO}_{2}, \mathrm{Fe}_{3} \mathrm{O}_{4}, \mathrm{SiO}_{2}{ }^{(27,28)}$ and others have been used.

Nitrocellulose is one of the oldest and most widely used film formers adaptable to a number of wide applications such as in protective and decorative coatings for wood and metal, flexible coatings for paper, foil and plastic films, printing inks, and adhesives ${ }^{(29)}$. The film-forming and keying properties of nitrocellulose are outstandingly good ${ }^{(30)}$. Nitrocellulose is characterized by its thermoplastic behavior, fast solvent evaporation, good compatibility with a wide range of materials, excellent processability and good mechanical properties ${ }^{(29,31)}$. Due to a unique combination of properties, celluloses are a good choice to disperse the electrically conductive materials (PANI and Ag-NPs) in it ${ }^{(32,33)}$.

The electrically conductive metallic inks have various electronic applications including flat panel displays (FPD), semiconductor packaging, photovoltaic cells, and micro-electromechanical systems (MEMS), plasma displays (PDP), radio frequency identification (RFID) and photovoltaic solar cells ${ }^{(34)}$.

Generally, corporation of conducting polymer and metallic particles with polymeric materials lead to make a desirable product with integrated properties to be suitable for a wide variety applications ${ }^{(35-36)}$.

Due to the large deficiency in literature concerning the developments of conductive ink nano-composites based in cellulosic nitrate, this work was demonstrated to prepare conductive ink nano-composite based on poly aniline hydrochloride, silver nano-particles and nitrocellulose.

\section{Materials}

\section{Materials and Methods}

Aniline (99.5\%, Sigma-Aldrich), potassium peroxydisulphate (98\%, Labmerk Chemicals Pvt. Ltd.), hydrochloric acid (34-36\%, El-Nasr for intermediate chemicals Co.), ethanol (96\% absolute, ALAMIA Co.), silver nitrate ( $\geq 99 \%$, Sigma-Aldrich), oleyl amine and oleic acid (technical grade $70 \%$, SigmaAldrich), methanol for HPLC (99.9\%, Sigma-Aldrich), n-hexane (99\%, SigmaAldrich), toluene (99.5\%, Scharlau), nitrocellulose (NC) lower nitrogen content was commercial material.

\section{Methods}

In this method, PANI was synthesized firstly, then Ag-NPs was synthesized individually, then both of PANI and Ag-NPs was dispersed in suitable solvent also individually then both solutions of PANI and Ag-NPs were dispersed in nitrocellulose solution. 
Synthesis of PANI conducting polymer

After twice distillation, $(2 \mathrm{ml}, 0.022$ mole) of aniline was added to $10 \mathrm{ml}$ absolute ethanol and placed in ice bath $\left(0-5{ }^{\circ} \mathrm{C}\right)$ with continuous stirring. $5.5 \mathrm{ml}$ of $0.1 \mathrm{M} \mathrm{HCl}$ solution was added then also solution of $(6 \mathrm{~g}, 0.022$ mole $)$ potassium peroxydisulphate in $100 \mathrm{ml}$ distilled water was added dropwise. The color of reaction medium was changed to reddish brown after addition of first $5 \mathrm{ml}$ of potassium peroxydisulphate solution then to dark green color. After $1 \mathrm{hr}$ of continuous stirring, the reaction medium was remained to stand for $24 \mathrm{hr}$. Precipitate was separated by filtration, then washed with $200 \mathrm{ml}$ warm distilled water and $100 \mathrm{ml}$ ethanol and left to dry in an oven at $80{ }^{\circ} \mathrm{c}$ for $4 \mathrm{hr}$. Further doping of PANI was done in $100 \mathrm{ml}$ of $2 \mathrm{M} \mathrm{HCl}$ for $2 \mathrm{hr}$ at room temperature and then the product was filtered and dried.

\section{Synthesis of Ag-NPs}

Silver nitrate $\mathrm{AgNO}_{3}$ was used as a source of $\mathrm{Ag}$ metal particles, while a mixture of oleyl amine (OAm) and oleic acid (OAc) was used as reducing and capping agents to control both the morphology and the size of the Ag metal nanoparticles. The synthesis of Ag-NPs was as the following:

$\mathrm{AgNO}_{3}(0.01 \mathrm{~g})$ was dissolved in a mixture of $5 \mathrm{ml}$ oleyl amine and $3 \mathrm{ml}$ of oleic acid whereas the dissolution was occurring by sonication. The chemical reaction was accelerated by leaving the reaction mixture in microwave device for $1 \mathrm{~min}$. The color of reaction medium changed from yellow to brown after getting out from microwave device.

$10 \mathrm{ml}$ of methanol was added to the mixture, then the nanoparticles were precipitated out and the flocculate was separated from the supernatant by centrifugation. Dispersion of the flocculate in $2 \mathrm{ml}$ of toluene and $5 \mathrm{ml}$ of methanol followed by further centrifugation. This step was repeated to obtain pure nano-particles. Finally, the precipitated nanoparticles were dispersed in $5 \mathrm{ml}$ hexane, then dried at $40^{\circ} \mathrm{C}$ in the oven and collected as powder.

Preparation of conductive ink nano-composite (PANI, Ag-NPs, NC)

Firstly, the conductive ink nano-composite was prepared as the following: 0.1 $\mathrm{g}$ Ag-NPs was dispersed in chloroform, $0.04 \mathrm{~g}$ PANI was dispersed in chloroform, $0.2 \mathrm{~g} \mathrm{NC}$ dissolved in ethanol. The dispersion occurred by sonication for $2 \mathrm{hr}$. After dispersion occurred, the three components were mixed with each other, then the mixture was sonicated for $10 \mathrm{~min}$ after that, the composite has been ready to drawdown by the spin coater to form film on glass slit to be ready for measuring the electrical conductivity.

\section{Characterization}

PANI was characterized with UV-vis spectroscopy, FT-IR, Thermal gravimetric analysis (TGA), Differential Scanning Calorimetry (DSC) while AgNPs was characterized by UV-vis and TEM whereas PANI and (PANI, Ag-NPs, NC) composite was measured by four-point probe method to assay the electrical conductivity. 
The conductivity of the sample was measured by the use of four-probe technique on pellets compressed for PANI at $600 \mathrm{MPa}, 13 \mathrm{~mm}$ in diameter and 1-1.5 mm thick and by using spin coater for (PANI, Ag-NPs, NC) composite, using a Keithley resistivity range $0-200$ mega ohm and at 200 volts at room temperature. The sample of a composite for conductivity measurement was prepared by drawdown the composite solution on glass slit by spin coating technique then evaporation of solvents was occurred.

FT-IR spectra were taken with $\mathrm{KBr}$ pellets by using JASCO 4100-A FT-IR spectrometer, UV-vis spectra were obtained by the use of Shimadzu UV-1600 series spectrophotometer. TGA was made by using Shimadzu DTG-60H under Nitrogen Atmosphere with gas flow rate $20 \mathrm{ml} / \mathrm{min}$ at heating rate $10^{\circ} \mathrm{c} / \mathrm{min}$ in the temperature range $0-700{ }^{\circ} \mathrm{C}$. Differential Scanning Calorimetry (DSC) was carried out by using Shimadzu DSC-60 under Nitrogen Atmosphere with gas flow rate 20 $\mathrm{ml} / \mathrm{min}$ at heating rate $10^{\circ} \mathrm{C} / \mathrm{min}$ in the temperature range $10-400{ }^{\circ} \mathrm{C}$.

The shape and size of the Ag-NPs were evidenced by JEM-2100 Transmission electron microscopy (TEM) operated at $200 \mathrm{kV}$. Sample for TEM was prepared by placing a droplet of a colloid suspension in toluene for organic media on a carbon-coated, 300-mesh copper grid (Ted Pella) and allowed to evaporate in air at room temperature.

PANI analysis

\section{Results and Discussion}

FT-IR spectroscopic analysis

Figure 1 illustrates the FTIR spectrum of PANI doped with $\mathrm{HCl}$ acid.

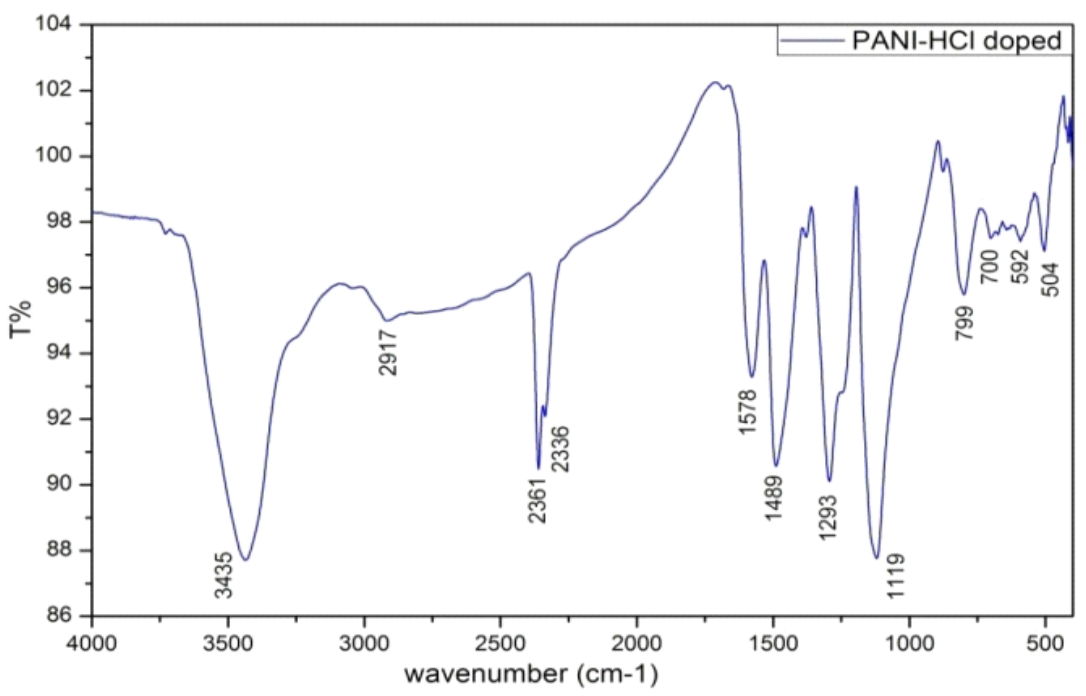

Fig. 1. FT-IR spectra of PANI doped with HCl acid.

Egypt. J. Chem. 59, No.4 (2016) 
It is clearly seen from the figure that there are characteristic absorption bands as shown in Table 1 where, N-H stretching band for secondary amine at $3435 \mathrm{~cm}^{-1}$, the $\mathrm{N}-\mathrm{H}$ wagging band for secondary amines appears at $700 \mathrm{~cm}^{-1}$ and the band at 1293 $\mathrm{cm}^{-1}$ represent $\mathrm{C}-\mathrm{N}$ stretching bands secondary aromatic amine ${ }^{(14,37)}$. The main bands of protonated PANI are bands at $1578 \mathrm{~cm}^{-1}$ and $1489 \mathrm{~cm}^{-1}$ can represent the stretching vibration of the quinonoid and benzenoid rings "the band at $1578 \mathrm{~cm}^{-1}$ arises from $\mathrm{C}=\mathrm{C}$ of quinonoid rings (Q) while the band at $1489 \mathrm{~cm}^{-1}$ is due to

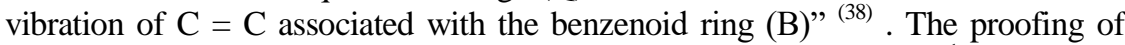
protonation "doping" to PANI is through band appearing at $2361 \mathrm{~cm}^{-1}$ that present stretching vibration of $\left(\mathrm{NH}^{+}\right)$tertiary amine salt ${ }^{(39)}$. The band indicating the polymer formation is the band located at $799 \mathrm{~cm}^{-1}$ that is characteristic of para distributed aromatic rings $(38,40,41)$.

The strong band at $1119 \mathrm{~cm}^{-1}$ and broad strong absorption tail at 2300-2700 $\mathrm{cm}^{-1}$ are appearing due to stretching vibration of $\mathrm{B}-\mathrm{NH}^{+}=\mathrm{Q}$ where those two bands are considered the most important FTIR bands to evidence that high electrical conductivity and high degree of electron delocalization in polyanilines were found ${ }^{(42)}$.

TABLE 1. Assignments of main FTIR bands of PANI-HCl.

\begin{tabular}{|c|l|}
\hline Wavenumbers $\left(\mathbf{c m}^{-\mathbf{1}}\right)$ & \multicolumn{1}{|c|}{ Assignments } \\
\hline 3435 & $v(\mathrm{~N}-\mathrm{H})$ stretching secondary amine \\
\hline 2917 & $v(\mathrm{C}-\mathrm{H})$ of Aromatic ring \\
\hline 2361,2336 & $v\left(\mathrm{NH}^{+}\right)$tertiary amine salt \\
\hline 1578 & $v(\mathrm{C}=\mathrm{C})$ of quinonoid rings \\
\hline 1489 & $v(\mathrm{C}=\mathrm{C})$ of benzenoid ring \\
\hline 1293 & $v(\mathrm{C}-\mathrm{N})$ in secondary amine \\
\hline 1119 & $v\left(\mathrm{~B}-\mathrm{NH}{ }^{+}=\mathrm{Q}\right)$ \\
\hline 1119,799 & $v$ of para substituent on Aromatic ring \\
\hline 700 & $\mathrm{~N}-\mathrm{H}$ wagging for secondary amine \\
\hline &
\end{tabular}

$U V$-vis spectroscopic analysis

Figure 2 shows the UV-vis spectrum of PANI. It can be illustrated from the figure that there are two characteristic absorption peaks; the evidence of formation of PANI conductive polymer is the max absorption peak at $206 \mathrm{~nm}$ that represents $\pi \rightarrow \pi^{*}$ transition of a conjugated ring system and absorption peak at $367 \mathrm{~nm}$ may be due to $n \rightarrow \pi^{*}$ transition of a lone pair of electron on imine. These results are in accordance with the data reported in previous study ${ }^{(43-49)}$. 


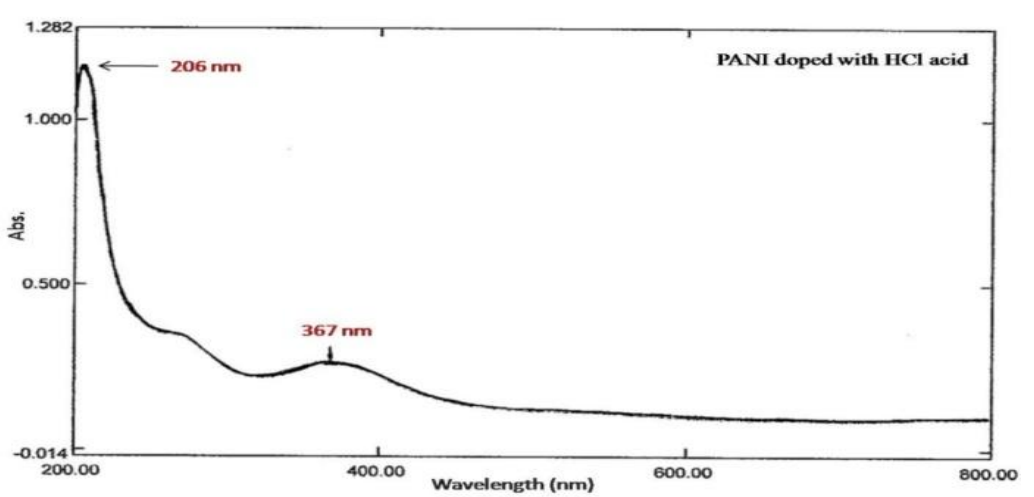

Fig. 2. UV-vis spectrum of PANI-HCl.

Thermal analysis

Thermal behavior of PANI can be identified by Thermal Gravimetric Analysis (TGA) and also by Differential Scanning Calorimetry (DSC); TGA is studying the thermal stability of PANI by measuring the weight loss of the polymer with changing the temperature and DSC is determining the glass transition temperatures $\left(\mathrm{T}_{\mathrm{g}}\right)^{(38)}$. The analysis occurred with measuring conditions that have been mentioned previously.

Figure 3 shows the weight loss of PANI from temperature $23{ }^{\circ} \mathrm{C}$ to $91{ }^{\circ} \mathrm{C}$; the weight loss of PANI sample is $7 \%$, this may be due to absorbed moisture, from $91{ }^{\circ} \mathrm{C}$ to $292{ }^{\circ} \mathrm{C}$ the sample decomposes gradually whereas from $292{ }^{\circ} \mathrm{C}$ to $610{ }^{\circ} \mathrm{C}$ the weight of sample decreases dramatically approximately $80 \%$ that due to degradation of polymer. So, the PANI has thermal stability up to $300{ }^{\circ} \mathrm{C}$.

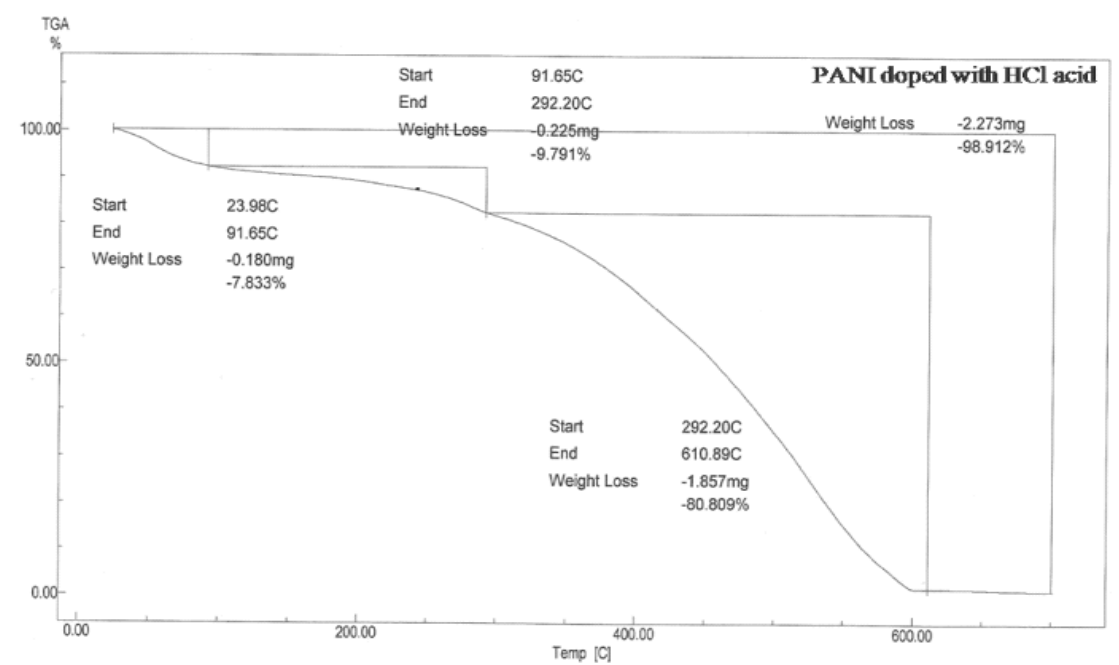

Fig. 3. TGA curve of PANI-HCl.

Egypt. J. Chem. 59, No.4 (2016) 
Figure 4 shows the DSC curve of PANI and there are two transitions on this curve; the first transition at $81{ }^{\circ} \mathrm{C}$ represents the glass transition temperature $\left(\mathrm{T}_{\mathrm{g}}\right)$ of polymer and the second transition at $262{ }^{\circ} \mathrm{C}$ is due to the start of polymer degradation.

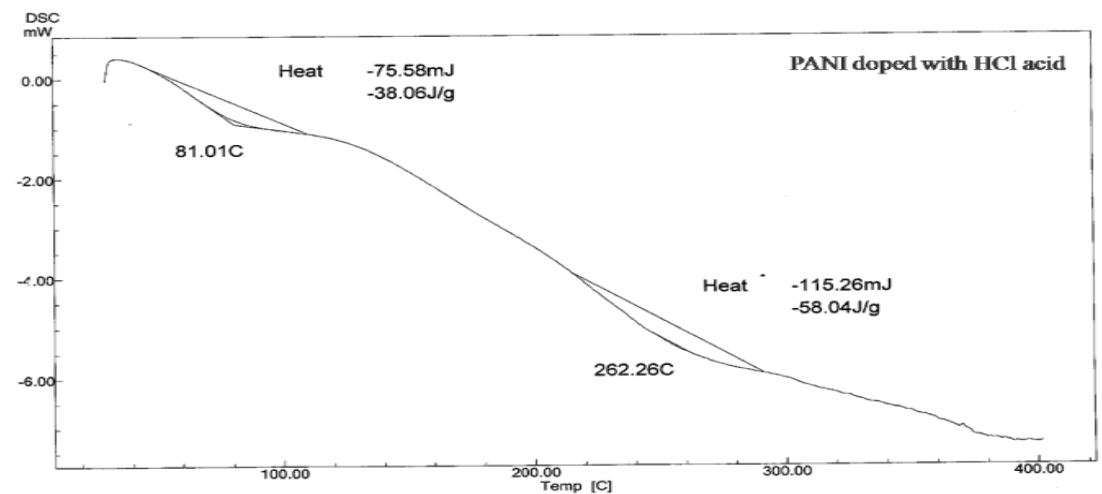

Fig. 4. DSC curve of PANI-HCI .

- Ag-NPs Analysis

TEM and $U V$-vis.

The max. Plasmon band at $416 \mathrm{~nm}$ is observed due to the formation of spherical Ag-NPs, as shown in Fig. 5. This means that (OAc-OAm) could act as both a reducing agent and a capping material ${ }^{(50)}$. The onset of the color changes from yellow to brown corresponding to the formation of Ag-NPs. The image of TEM is an evidence for the formation of Ag-NPs as shows in Fig. 6 whereas the spherical shape shows at scale bar $20 \mathrm{~nm}, 50 \mathrm{~nm}$ and $100 \mathrm{~nm}$. Histogram (Fig. 7) showed the particle size distribution of $\mathrm{Ag}$ particles and gave a particle size average approximately equal $18 \mathrm{~nm}$.

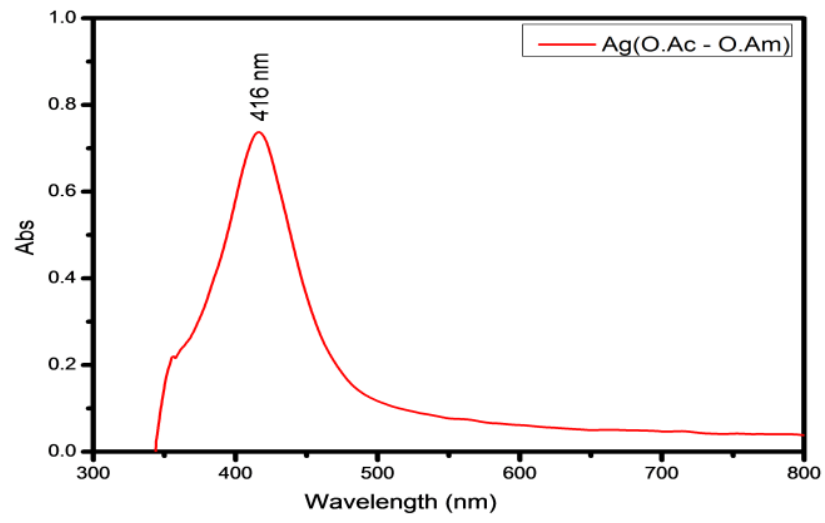

Fig. 5. UV-vis spectrum of Ag-NPs .

Egypt. J. Chem. 59, No. 4 (2016) 


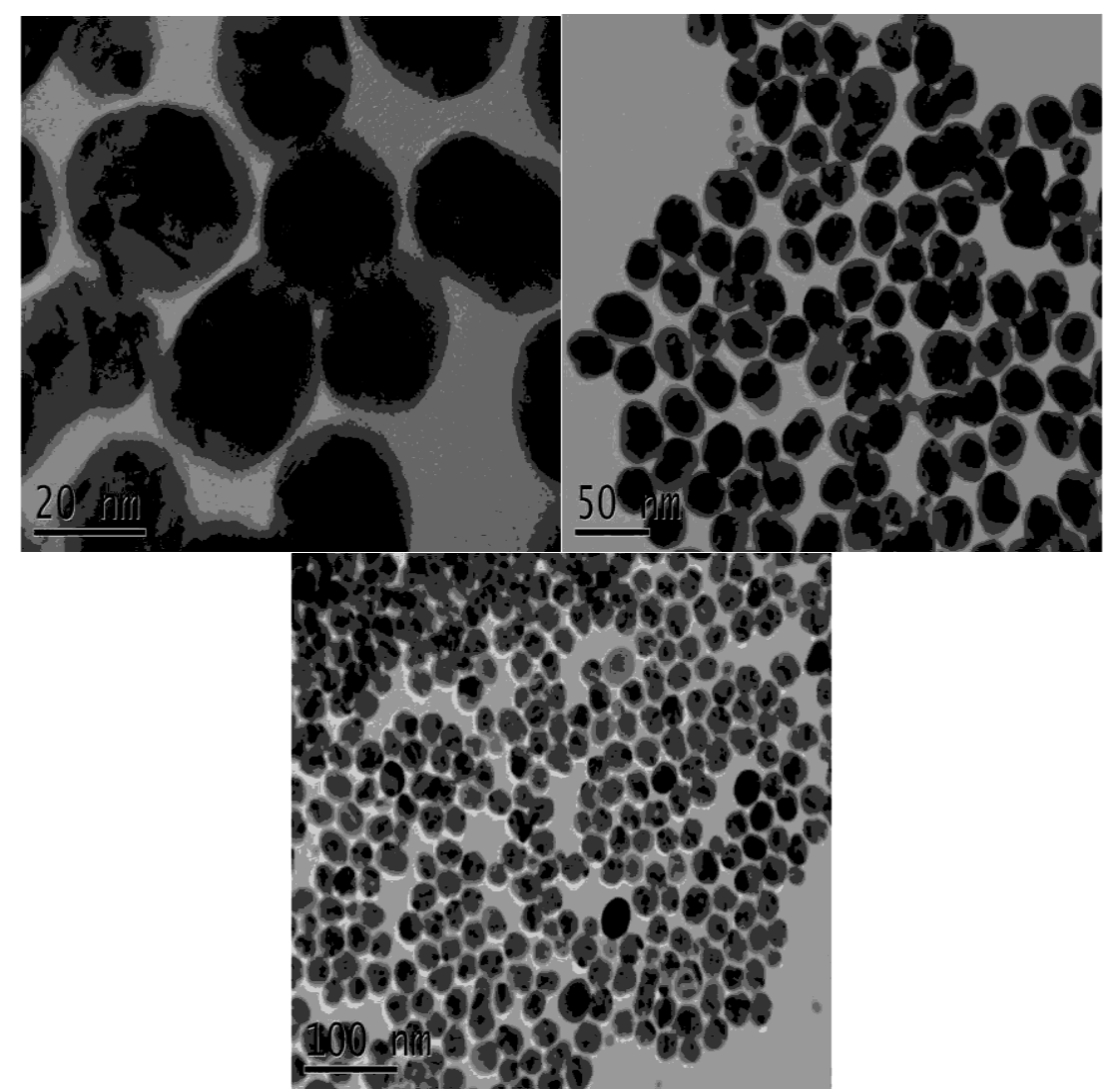

Fig. 6. TEM image of Ag-NPs (a) scale bar $20 \mathrm{~nm}$, (b) $50 \mathrm{~nm}$ and (c) $100 \mathrm{~nm}$.

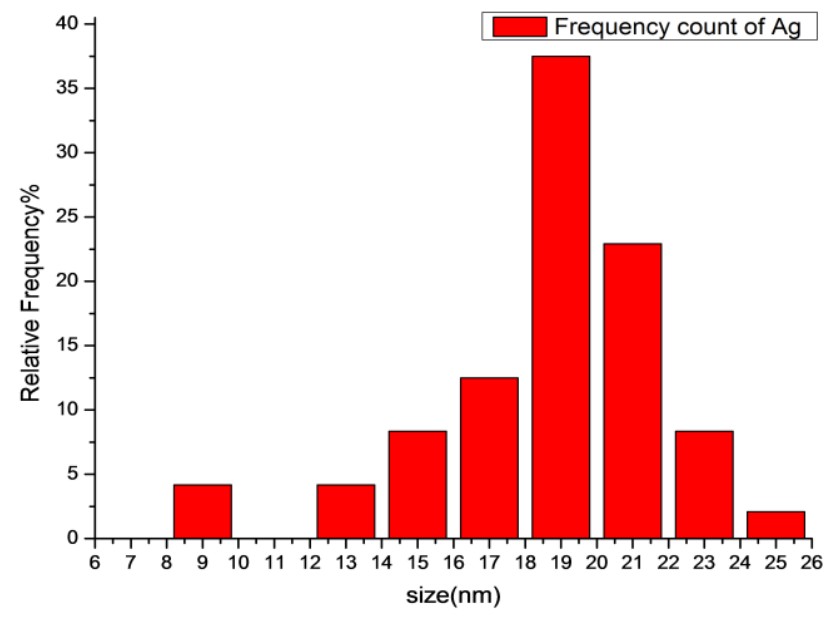

Fig. 7. Histogram shows particle size distribution of Ag-NPs .

Egypt. J. Chem. 59, No.4 (2016) 
Electrical conductivity analysis

The electrical conductivity assay of PANI pellet was $4.8 \times 10^{-2} \mathrm{~S} / \mathrm{cm}$ whereas the electrical conductivity of the film of (PANI, Ag-NPs, NC) composite was $0.6 \mathrm{~S} / \mathrm{cm}$. This result is to be considered good for this first composite made from these three components.

\section{Conclusion}

The prepared novel conductive ink nano-composite of (Poly aniline, Silver nanoparticles, Nitrocellulose) with percentage ratio (27:66:7) respectively and with spherical Ag-NPs with average particle size $18 \mathrm{~nm}$, showed electrical conductivity of $0.6 \mathrm{~S} / \mathrm{cm}$. This result produces a new composite with integrated properties that can be useful for conductive ink applications and other advanced technologies.

Acknowledgments: The authors would like to thank Ahmed Ibrahim Abd ElSalam, Ahmed Shehata and Mohamed Mohsen for helpful support.

\section{References}

1. Li, N. Lu, D. and Wong, C.P., Ch7: Conductive Nano-Inks, In: Electrical Conductive Adhesives with Nanotechnologies. Springer (2010).

2. Daoqiang Daniel Lu, Yi Grace Li, and Wong, C.P. Ch10: Nanoconductive Adhesives, In: Nanopackaging: Nanotechnologies and Electronics Packaging, J.E. Morris, Editor. Springer (2008).

3. Abd El-Ghaffar, M.A., Youssef, A.M. and Abd El-Hakim, A.A., Polyaniline nanocomposites via in situ emulsion polymerization based on montmorillonite:Preparation and characterization. Arabian Journal of Chemistry, in press (2014).

4. Abd El-Ghaffar, M.A., Shaffei, K.A. and Abdelwahab, N.A., Evaluation of some conducting polymers as novel antioxidants for rubber vulcanizates. International Journal of Polymer Science, 1- 9 (2014).

5. Leo'n, C.P., Campbell, S.A., Smith, J.R. and Walsh, F.C., Conducting polymer coatings in electrochemical technology:Part 2 - Application areas. Transactions of the Institute of Metal Finishing, 86(1), 34-40 (2008).

6. Desilvestro, J., Scheifele, W. and Haas, O., In situ determination of gravimetric and volumetric charge-densities of battery electrodes-Polyaniline in aqueous and nonaqueous electrolytes. J. Electrochem Soc., 139(10), 2727-2736 (1992).

7. Joo, J. and Epstein, A.J., Electromagnetic-radiation shielding by intrinsically conducting polymers. Appl. Phys. Lett., 65(18), 2278-2280 (1994).

8. Trivedi, D.C. and Dhawan, S.K., Shielding of electromagnetic-interference using polyaniline. Synth. Met., 59(2), 267-272 (1993).

Egypt. J. Chem. 59, No. 4 (2016) 
9. Ismail, M.N., Abd El-Ghaffar, M.A., Shaffei, K.A. and Mohamed, N.A., Some novel polyamines as antioxidants for SBR vulcanizates. Polymer Degradation and Stability, 63, 377-383 (1999).

10. Stejskal, J., Sapurina, I. and Trchová, M., Polyaniline nanostructures and the role of aniline oligomers in their formation. Progress in Polymer Science, 35, 1420-1481 (2010).

11. Trivedi, D.C., Polyanilines Handbook of Organic Conductive Molecules and Polymers.Conductive Polymers: Synthesis and Electrical Properties, H.S. Nalwa. (Ed.)Vol. 2. New York: John Wiley \& Sons. (1997).

12. Bhattacharya, A. and De, A., Conducting composites of polypyrrole and polyaniline a review. Prog. Solid State Chem. 24(3), 141-181 (1996).

13. Saxena, V. and Malhotra, B.D., Prospects of conducting polymers in molecular electronics. Curr. Appl. Phys. 3(2-3), 293-305 (2003).

14. Ismail, M.N., Ibrahim, M.S. and Abd El-Ghaffar, M.A., Polyaniline as an antioxidant and antirad in SBR vulcanizates. Polymer Degradation and Stability, 62(2), 337-341 (1998).

15. Sarfraz, J., Ihalainen, P., Määttänen, A., Peltonen, J. and Lindén, M., Printed hydrogen sulfide gas sensor on paper substrate based on polyaniline composite. Thin Solid Films, 534(Complete), 621-628 (2013).

16. Arau jo, P.L.B., Arau'jo, E.S., Santos, R.F.S. and Pacheco, A.P.L., Synthesis and morphological characterization of PMMA/polyaniline nanofiber composites. Microelectronics Journal, 36, 1055-1057 (2005).

17. Vasant Chabukswar and Sanjay Bhavsar, Synthesis and characterization of organically soluble and electrically conducting acid doped polyaniline. Chemistry \& Chemical Technology, 4(4), 277-280 (2010).

18. Veluru, J.B., Satheesh, K., Trivedi, D., Ramakrishna, M.V. and Srinivasan, N.T., Electrical properties of electrospun fibers of PANI-PMMA composites. J. Eng. Fibers Fabrics, 2, 25-31. (2007).

19. Pan, M., Zhang, C., Liu, B. and Mu, J., Dielectric and thermal properties of epoxy resin nanocomposites containing polyhedral oligomeric silsesquioxane. Journal of Materials Science Research, 2(1), 153-162. (2013).

20. Agunsoye, J.O., Talabi, S.I., Hassan, S.B., Awe, I.O., Bello, S.A. and Aziakpono, E., The development and characterisation of aluminium dross-epoxy resin composite materials. Journal of Materials Science Research, 3(2), (2014).

21. Ho, K.S. Hsieh, K.H., Huang, S.K. and Hsieh, T.H., Polyurethane-based conducting polymer blends I. Effect of chain extender. Synthetic Metals, 107, 65-73 (1999). 
22. Zareh, E.N., Moghadam, P.N. Azariyan, E. and Sharifian, I., Conductive and biodegradable polyaniline/starch blends and their composites with polystyrene. Iranian Polymer Journal, 20(4), 319-328 (2011).

23. AbdEl-Ghaffar, M.A., Youssef, A.M. and Abd El-Hakim, A.A., Polyaniline nanocomposites via in situ emulsion polymerization based on montmorillonite: Preparation and characterization. Arabian Journal of Chemistry, in press (2014).

24. Goswami, S., Maiti, U.N., Maiti, S., Nandy, S. Mitra, M.K. and Chattopadhyay, K.K., Preparation of graphene-polyaniline composites by simple chemical procedure and its improved field emission properties. CARBON, 49, 2245$2252(2011)$.

25. Lee, B., Kim, Y., Yang, S., Jeong, I. and Moon, J., $A$ low-cure-temperature copper nano ink for highly conductive printed electrodes. Current Appl. Phys., in press (2009).

26. Lu, X., Zhang, W., Wang, C., Wen, T. C. and Wei, Y., One-dimensional conducting polymer nanocomposites:Synthesis, properties and applications. Prog. Polym. Sci., 36, 671-712 (2011).

27. Huang, X., Wang, G., Yang, M., Guo, W. and Gao, H., Synthesis of polyaniline-modified $\mathrm{Fe} 3 \mathrm{O} 4 / \mathrm{SiO} 2 / \mathrm{TiO} 2$ composite microspheres and their photocatalytic application. Materials Letters, 65(19-20), 2887-2890 (2011).

28. Mahulikar, P.P., Jadhav, R.S. and Hundiwale, D.G., Performance of polyaniline/TiO2 nanocomposites in epoxy for corrosion resistant coatings. Iran Polym J., 20, 367-376 (2011).

29. Zavisza, D.M. Ch 63: Nitrocellulose, In: Coatings Technology Handbook, $3^{\text {rd }}$ ed., A.A. Tracton, Editor. Taylor \& Francis Group, LLC. (2006).

30. Leach, R.H. and Pierce, R.J. CH4:Raw materials, In: The Printing Ink Manual, R.H. Leach and R.J. Pierce, Editors. Springer. (2007).

31. Nitrocellulose. Dow Wolff Cellulosics. www.dowwolffcellulosics.com.

32. Naderizadeh, B., Moghimi, A. and Shahi, M. Electrospun nitrocellulose and composite nanofibers. JNS, 2, 287-293 (2012).

33. Pinto, R.J., Neves, M.C., Neto, C.P. and Trindade, T., Composites of Cellulose and Metal Nanoparticles. Nanocomposites-New Trends and Developments (2012).

34. Lee, J.J., Park, J. Kim, M.H. Chang, T. Kim, S.T. Koo, S.M. You, Y.C. and Lee, S.J., Silver complex inks for ink-jet printing: the synthesis and conversion to a metallic particulate ink. Journal of Ceramic Processing Research, 8(3), 219. (2007).

35. Kato, M. and Usuki, A. Polyamide/clay nanocomposites, In: Polymer Nanocomposites, Y.-W. Mai and Z.-Z. Yu, Editors. CRC Press (2006). 
36. Liepins, R. Ch 91: Conductive Coatings, In: Coatings Technology Handbook, 3rd ed., A.A. Tracton, Editor. Taylor \& Francis Group, LLC (2006).

37. Stuart, B. Infrared Spectroscopy. Wiley Online Library (2005).

38. Porramezan, M. and Eisazadeh, H., Fabrication and Characterization of Polyaniline Nanocomposite Modified with $\mathrm{Ag}_{2} \mathrm{O}$ Nanoparticles. Composites: Part B (2011).

39. Julian, J.M. and Brezinski, D.R., An Infrared Spectroscopy Atlas for the Coatings Industry. Federation of Societies for Coatings Technology (1991).

40. Stejskal, J. and Gilbert, R.G. Poly aniline: preparation of conducting polymer. Pure Appl. Chem., 5(74), 857-867 (2002).

41. Shukla, S.K., Bharadvaja, A., Tiwari, A., Parashar, G.K. and Dubey, G.C., Synthesis and characterization of highly crystalline polyaniline film promising for humid sensor. Adv. Mat. Lett. 1(2), 129-134 (2010).

42. Marjanovic', I., Juranic', B., iric'-Marjanovic, G.C.,' Pašti, I., Trchová, M. and Holler, P. Chemical oxidative polymerization of benzocaine. Reactive \& Functional Polymers, 71, 704-712 (2011).

43. Atassi, Y., Tally, M. and Ismail, M., Synthesis and characterization of chloride doped polyaniline by bulk oxidative chemical polymerization. Doping effect on electrical conductivity. Higher Institute for Applied Sciences and Technology, HIAST, P.O. Box 31983, Damascus, Syria. Corresponding author e-mail address: Yomen_Atassi@hiast.edu.sy.http://arxiv.org/ftp/arxiv/papers/0809/0809.3552.pdf.

44. Guo, Y., He, D., Xia, S., Xie, X., Gao, X., Zhang, Q. and Obare, S., Preparation of a novel nanocomposite of polyaniline core decorated with anatase-TiO 2 nanoparticles in ionic liquid/water microemulsion. Journal of Nanomaterials, 2011. (906), p. 32. (2012).

45. Toshima, N. and Yan, H., Chemical preparation of polyaniline and its derivatives by using cerium (IV) sulfate. Novel preparation of polyxylidines. Bulletin of the Chemical Society of Japan, 68(3), 1056 (1995).

46. Xing, S. Jing, S., Zhao, C. and Wang, Z., Effect of addition of organic solvents on properties of the chemically synthesized polyaniline in aqueous solutions. $E$ polymers (2007).

47. Molapo, K.M., Ndangili, P.M., Ajayi, R.F. Mbambisa, G., Mailu, S.M., Njomo, N. Masikini, M. Baker, P. and Iwuoha, E.I. Electronics of conjugated polymers (I): polyaniline. Int. J. Electrochem. Sci. 7, 11859 - 11875( 2012).

48. Kanwal, F., Gul, A., and Jamil, T., Synthesis of acid doped conducting polyaniline. Journal of the Chemical Society of Pakistan, 29(6), 553-557 (2007).

49. Vivekanandan, J., Ponnusamy, V., Mahudeswaran, A. and Vijayanand, P.S., Synthesis, characterization and conductivity study of polyaniline prepared by

Egypt. J. Chem. 59, No.4 (2016) 
chemical oxidative and electrochemical methods. Arch. Appl. Sci. Res., 3(6),147-153 (2011).

50. Mohamed, Mona B., AbouZeid, Kh.M., Abdelsayed, V., Aljarash, A.A. and ElShall, M.S. Growth mechanism of anisotropic gold nanocrystals via microwave synthesis:formation of dioleamide by gold nanocatalysis. ACS NANO, 4(5), 27662772 (2010).

(Received 15/12/2015;

accepted 26/6/2016) 


\title{
حبر جديد موصل للكهرباء مبني على متراكب (البولي أنيلين، حبيات الفضة النانومترية، راتتج النيتروسيليلوز)
}

\author{
محمود أحمد عبد الففار 1 ، خالد أحمد شافعي2 ، أمينة فؤاد زكـري² منى بكر

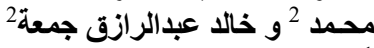

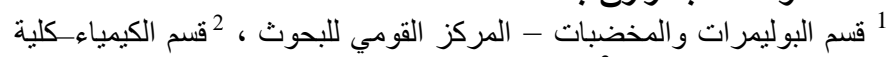

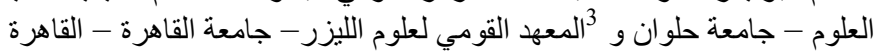

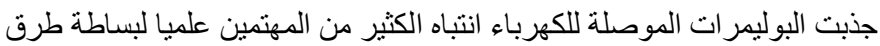

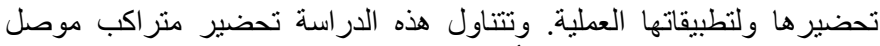

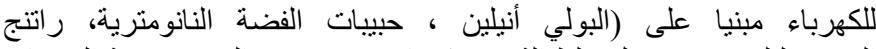

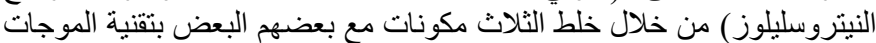

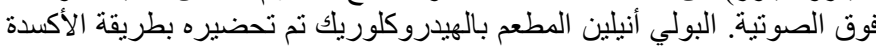

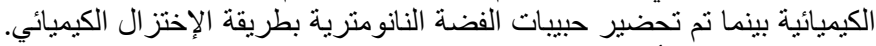

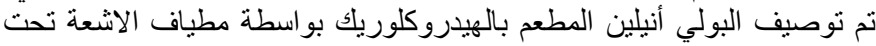

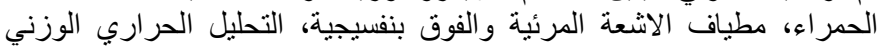

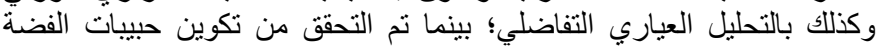

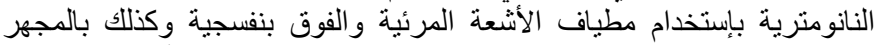

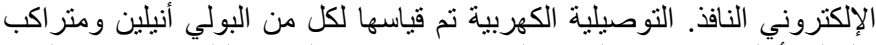

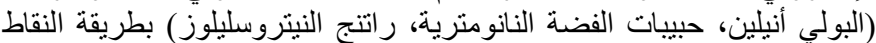

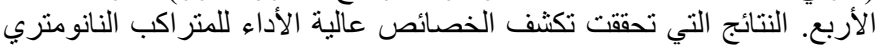

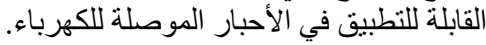

